\title{
A FAMILY OF GROENOUW'S DYSTROPHY
}

BY

\author{
E. V. SRINIVASAN \\ MADRAS
}

WhAT appeared as nodular dystrophy of Groenouw with focal illumination and corneal loupe turned out to be lattice-shaped dystrophy in the three oldest ones of the following family under the slit-lamp microscope.

Regular ribbon-shaped bands were seen traversing irregularly throughout the middle two-thirds of the cornea, the branching becoming less dispersed towards the periphery. The cornea between the bands is quite cloudy under the microscope. The posterior cornea showed irregular amorphous masses, pure white in colour, not exceeding the width of two laths of the lattice, and hanging, as it were, in the clear aqueous, giving one the impression that they are floating bodies, but on long continued examination under the slip-lamp it was found that every one of the lumps was fixed and immobile.

These white masses that were fairly well distributed in Descemet's membrane were absent in the younger members and, in fact, the appearance of the dystrophy was of the pure nodular variety.

The macroscopically clear corneae of the youngest members showed the commencing dystrophy in the form of superficial punctate keratitis, the curdy spots being mostly on the corneal nerves.

None of the members showed hypotony and all of them are females.

Patient $\mathrm{N}$. only consulted me regarding her headache and photophobia. The others have no symptoms and were brought for inspection on my request.

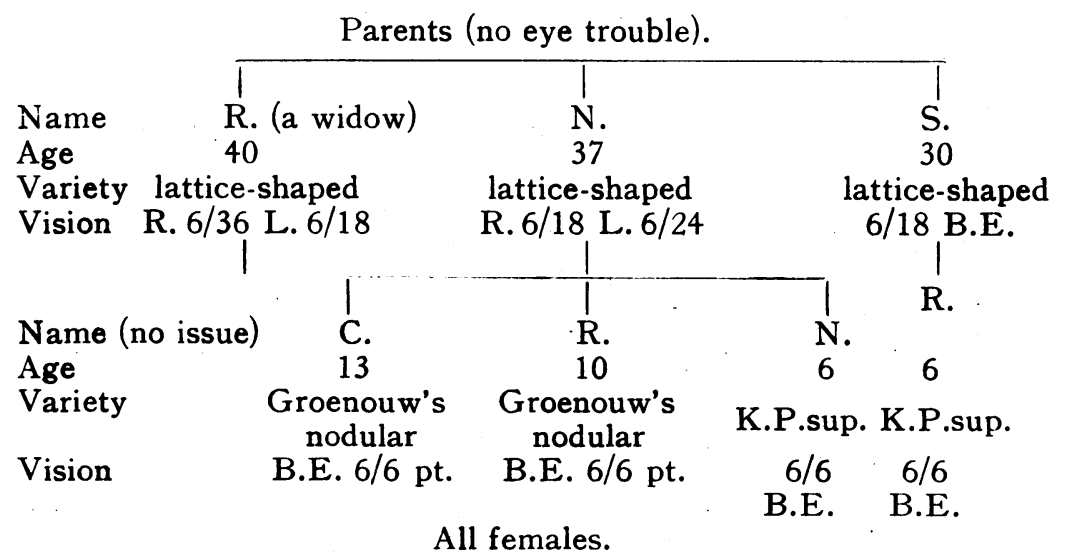

All females. 